Check for updates

Cite this: Nanoscale Adv., 2019, 1, 2953

\title{
Rapid synthesis of ultrasmall platinum nanoparticles supported on macroporous cellulose fibers for catalysis
}

\author{
Md. Tariqul Islam, (D) *ab Jose A. Rosales, ${ }^{a}$ Ricardo Saenz-Arana, ${ }^{a}$ \\ Shahrouz J. Ghadimi ${ }^{\text {bc }}$ and Juan C. Noveron ${ }^{\star a b}$
}

\begin{abstract}
Herein, we report a facile method for the synthesis of platinum nanoparticles (PtNPs) about $2.25 \mathrm{~nm}$ in size by heating a solution of chloroplatinic acid and sodium rhodizonate. The PtNPs were synthesized in about $5 \mathrm{~min}$. The PtNPs were supported on macroporous cellulose fibers that were obtained from Kimwipe paper (KWP). The cellulose fiber-supported PtNPs (PtNPs@KWP) exhibited excellent catalytic activity towards the reduction of organic pollutants [e.g. methyl orange $(\mathrm{MO})$ ] in the presence of hydrogen $\left(\mathrm{H}_{2}\right)$ gas and formic acid (FA). FA and $\mathrm{H}_{2}$ gas were utilized as clean and alternative reducing agents. The reduction of $\mathrm{MO}$ was performed in two different types of water matrices viz. deionized water (DIW) and simulated fresh drinking water (FDW). In both water matrices, the FA mediated reduction of MO was found to be faster than the $\mathrm{H}_{2}$ gas-bubbled one. The PtNPs@KWP demonstrated excellent cycling stability without leaching the PtNPs or platinum ions into the solution for at least five cycles.
\end{abstract}

Received 26th February 2019

Accepted 3rd June 2019

DOI: $10.1039 / \mathrm{c} 9 \mathrm{na00124g}$

rsc.li/nanoscale-advances

Therefore, the utilization of cleaner reducing agents could be

\section{Introduction}

Noble metal nanoparticles (NPs) possess extraordinary catalytic properties that are highly dependent on their size, shape, and composition..$^{1-5}$ As a result, noble metal NPs are extensively utilized for a number of chemical transformations such as de/ hydrogenations ${ }^{6,7}$ oxidation, ${ }^{8}$ alkylation, ${ }^{9}$ and coupling reactions. ${ }^{10}$ Recently, noble metal NP-based catalytic processes have become intriguing and effective methods for water or wastewater treatment technologies. ${ }^{11-13}$ Catalytic processes have advantages over other methods. For instance, catalytic processes are fast and can essentially transform or degrade hazardous pollutants into non- or less-hazardous species, while other methods may transfer the pollutants from one phase to another. ${ }^{14,15}$

One of the important and widely studied catalytic reactions is the reduction of organic pollutants, where sodium borohydride $\left(\mathrm{NaBH}_{4}\right)$ is most commonly used as the reducing agent. ${ }^{16-18}$ However, the major drawback of $\mathrm{NaBH}_{4}$ is the generation of by-products (e.g. $\mathrm{BO}_{2}{ }^{-}$and $\left.\mathrm{BO}_{3}{ }^{3-}\right)$ that are also known as secondary pollutants. The removal of these byproducts from water becomes even more challenging.

\footnotetext{
${ }^{a}$ Department of Chemistry and Biochemistry, University of Texas at El Paso, 500 West University Avenue, El Paso, TX 79968, USA. E-mail: mtislam@miners.utep.edu; tariqul.lab@gmail.com; jcnoveron@utep.edu

${ }^{b}$ NSF Nanosystems Engineering Research Center for Nanotechnology Enabled Water Treatment (NEWT), USA

'Department of Civil Engineering, University of Texas at El Paso, 500 West University Avenue, El Paso, TX 79968, USA
} highly beneficial in regard to water or wastewater treatment. From this aspect, formic acid (FA) could be employed as an alternative reducing agent. The catalytic oxidation of FA (also known as the decomposition of $\mathrm{FA}$ ) generates $\mathrm{H}_{2}, \mathrm{H}_{2} \mathrm{O}, \mathrm{CO}$, and $\mathrm{CO}_{2}$ via dehydrogenation ( $\mathrm{HCOOH} \rightarrow \mathrm{H}_{2}+\mathrm{CO}_{2}$ ) and dehydration $\left(\mathrm{HCOOH} \rightarrow \mathrm{H}_{2} \mathrm{O}+\mathrm{CO}\right)$ pathways. ${ }^{19,20}$ The $\mathrm{H}_{2}$ gas in situ generated via the dehydrogenation pathway has the ability to reduce organic and inorganic pollutants. ${ }^{21}$ For example, Lowry Gregory and Martin Reinhard reported the hydrodehalogenation of halogenated organic compounds in water using a palladium catalyst and $\mathrm{H}_{2}$ gas. ${ }^{22}$ Celebi Metin and colleagues reported the reduction of hexavalent chromium to trivalent chromium on palladium NPs by using FA. ${ }^{23}$ In addition to FA, the utilization of commercially available $\mathrm{H}_{2}$ gas could be a lucrative alternative to $\mathrm{NaBH}_{4}$. Although $\mathrm{H}_{2}$ gas is commonly utilized in the hydrogenation of organic compounds, there are few reports of its utilization in the reductive degradation of organic pollutants in water. ${ }^{24-26} \mathrm{FA}$ and $\mathrm{H}_{2}$ gas-induced catalytic reductions commonly require transition and/or noble metal NPs (e.g. Pt and Pd). ${ }^{27-29}$ In the case of FA, low pH can cause the transition metal catalysts to dissolve in aqueous solution. Therefore, there is a need for the utilization of noble metal NPs due to their chemical and physical robustness against FA. However, platinum and palladium nanoparticles are most effective in the formic acid oxidation and hydrogen induced catalytic reduction of organic and inorganic species.

In this study, the facile synthesis of ultrasmall platinum NPs (PtNPs) is reported employing sodium rhodizonate as the dual functional reducing-plus-stabilizing agent. The PtNPs were 
supported on macroporous cellulose fibers, obtained from Kimwipe paper (KWP). Cellulose fibers were chosen as the support because of their high binding affinity towards the PtNPs, good mechanical and chemical stability, abundance, low cost, and high surface area due to the porosity. ${ }^{30,31}$ The porous structure and high oxygen density (e.g. ether and hydroxyl functional groups) make cellulose fibers a strong support for metallic NPs. ${ }^{32}$ The cellulose fiber-based catalyst support also facilitated easier handling, recovery, and reuse of the catalyst. The PtNPs@KWP was applied as a catalyst for the reductive degradation of MO in water using $\mathrm{H}_{2}$ gas and FA. The $\mathrm{H}_{2}$ gas and FA were utilized as clean and alternative reducing agents to avoid secondary pollution. Methyl orange was used as a substrate and model organic pollutant because it is reported to be toxic, carcinogenic, and mutagenic to human beings and aquatic organisms. As an azo dye, MO is highly resistant to natural degradation. Therefore, efficient removal of azo dyes is an important requirement for water or wastewater treatment technologies. There are many reported methods for the decoration of ultrasmall platinum nanoparticles on various support materials such as polymer nanoshells, carbon, and nanostructured gold..$^{33-35}$ However, these methods are more sophisticated, need multiple steps, require a variety of chemicals, and long preparation time. As a result, these methods may not be adaptable for large-scale synthesis in the industry. In contrast, PtNPs@KWP synthesis, reported in this study, is novel, fast and very simple. Therefore, the method can be adapted for largescale synthesis in the industry. Additionally, the PtNPs@KWP could be carbonized to prepare carbon supported PtNP nanocomposites that could be utilized for a variety of catalytic applications.

\section{Materials and methods}

\subsection{Materials}

Sodium rhodizonate dibasic (97\%), hydrogen hexachloroplatinate(Iv) hydrate $\left(\mathrm{H}_{2} \mathrm{PtCl}_{6} \cdot 3 \mathrm{H}_{2} \mathrm{O} \geq 99.9 \%\right)$, and $\mathrm{MO}$ were purchased from Amresco and Kimtech KWP was purchased Fisher Scientific, USA. Formic acid $(\geq 98 \%)$ was purchased from BDH Chemicals while $\mathrm{H}_{2}$ gas (99.99\%) was obtained from Matheson Tri-Gas. Milli-Q water ( $>18.20 \mathrm{MI} \mathrm{cm}$ resistivity) was obtained from a Milli-Q (Advantage A-10) water filter system. The simulated fresh drinking water was prepared following the Nanotechnology Enabled Water Treatment (NEWT) protocol. In detail, $252 \mathrm{mg} \mathrm{L}{ }^{-1} \mathrm{NaHCO}_{3}, 147 \mathrm{mg} \mathrm{L} \mathrm{L}^{-1} \mathrm{CaCl}_{2} \cdot 2 \mathrm{H}_{2} \mathrm{O}$, $124 \mathrm{mg} \mathrm{L}{ }^{-1} \mathrm{MgSO}_{4} \cdot 7 \mathrm{H}_{2} \mathrm{O}, 95 \mathrm{mg} \mathrm{L}{ }^{-1} \mathrm{Na}_{2} \mathrm{SiO}_{3} \cdot 9 \mathrm{H}_{2} \mathrm{O}, 12 \mathrm{mg} \mathrm{L}{ }^{-1}$ $\mathrm{NaNO}_{3}, 2.2 \mathrm{mg} \mathrm{L}{ }^{-1} \mathrm{NaF}$, and $0.18 \mathrm{mg} \mathrm{L}{ }^{-1} \mathrm{NaH}_{2} \mathrm{PO}_{4} \cdot \mathrm{H}_{2} \mathrm{O}$ were dissolved in deionized water to achieve the simulated FDW.

\subsection{Characterization techniques}

Typical transmission electron microscopy (TEM) images were obtained using a Hitachi H-7650 transmission electron microscope with an accelerating voltage of $80 \mathrm{kV}$. High-resolution transmission electron microscopy (HRTEM) experiments were performed using a JEOL JEM3200FS electron microscope with an accelerating voltage of $300 \mathrm{kV}$. Carbon-coated copper grids of 200 mesh (Electron Microscopy Science) were used for TEM imaging. About 5 microliters of the PtNP solution were deposited onto the grid and allowed to dry before imaging. For the TEM image of the PtNPs@KWP, few cellulose fibers were deposited on the grid and stained with uranyl acetate. ImageJ software was used to determine the average diameter and size distribution of the PtNPs using the TEM image. A Hitachi S-3400N Type II scanning electron microscope (SEM) equipped with an energy dispersive X-ray spectrometer with an accelerating voltage of $15 \mathrm{kV}$ was used to obtain the EDX spectrum. A carbon tape substrate was used for the SEM and EDX analysis of PtNPs. XRD was carried out using a Bruker D8 Discover XRD system with $\mathrm{Cu} \mathrm{K \alpha}$ radiation and a plastic substrate was used as the sample holder. For the XRD analysis, the PtNPs@KWP having 0.87\% Pt did not give a good signal for the PtNPs. Therefore, more PtNPs were deposited on the same PtNPs@KWP until a good signal was obtained from the PtNPs. The UV-Vis spectrum was obtained using an Agilent Cary 50 Conc UV-Visible spectrophotometer having a quartz cuvette with a path length of $10 \mathrm{~mm}$. A Micromeritics ASAP 2020 Surface Area and Porosity Analyzer was used to measure the nitrogen adsorption isotherms and to obtain the specific surface area. XPS data were collected using a Thermo Scientific Escalab 250Xi spectrometer with a six-channel detector. Photoelectrons were generated with a monochromatic $\mathrm{Al} \mathrm{K} \alpha(1486.68 \mathrm{eV}) \mathrm{X}$-ray source.

\subsection{Synthesis of PtNPs and the preparation of PtNPs@KWP}

The synthesis of PtNPs was carried out following our previously reported work. ${ }^{47}$ In a $100 \mathrm{~mL}$ round bottom flask, $20 \mathrm{~mL}$ of $0.5 \mathrm{mM}$ aqueous solution of $\mathrm{H}_{2} \mathrm{PtCl}_{6}$ was brought to boil and then $5 \mathrm{~mL}$ of $9.7 \mathrm{mM}$ sodium rhodizonate solution was injected into the $\mathrm{H}_{2} \mathrm{PtCl}_{6}$ solution with vigorous stirring (1200 rpm). The reaction mixture was further boiled for $5 \mathrm{~min}$ to ensure a complete reduction of the metal ions. Afterward, the reaction mixture was allowed to cool to room temperature and a single sheet of KWP, weighing about $456 \mathrm{mg}$, was immersed into the flask with occasional shaking by hand for about $5 \mathrm{~min}$. The binding of the PtNPs to the KWP could easily be observed by the color change of the KWP. The white color of the KWP turned grayish brown after binding with the PtNPs. The PtNPs@KWP was rinsed three times with deionized water and stored wet (without drying) under ambient conditions. ICP-OES was performed on the supernatant and washing solution and it was found that more than $99 \%$ of the PtNPs were bound on the KWP. The weight\% of the PtNPs on the KWP was calculated to be $0.87 \%$.

The PtNPs can be synthesized at room temperature by stirring a solution of sodium rhodizonate and chloroplatinic acid at ambient temperature for about $20 \mathrm{~min}$. It was found that the PtNP solution was highly stable when preserved under ambient conditions. The PtNP solution did not precipitate or aggregate after one year of preservation under ambient conditions.

\subsection{Catalytic activity of the PtNPs@KWP}

Two different types of reactions were carried out to study the catalytic performance of the PtNPs@KWP. The first reaction was the reduction of $\mathrm{MO}$ in the presence of excess $\mathrm{H}_{2}$ gas, where $\mathrm{H}_{2}$ gas acted as the reducing agent. The second reaction was the 
dual-catalytic oxidation of FA and the simultaneous reduction of MO. In this case, the decomposition of FA generated $\mathrm{H}_{2}$ gas and the in situ generated $\mathrm{H}_{2}$ gas was utilized for the reduction of MO.

2.4.1 $\mathrm{H}_{2}$ gas induced reduction of MO. In a $125 \mathrm{~mL}$ Erlenmeyer flask, $100 \mathrm{~mL}$ of 20 ppm MO solution was taken. A full PtNPs@KWP was immersed in the solution. Afterward, $\mathrm{H}_{2}$ gas was bubbled into the flask while the reaction mixture was gently stirred with a stirring bar. The reaction flask was kept open during the $\mathrm{H}_{2}$ gas bubbling. It was observed that the $\mathrm{H}_{2}$ gas bubbling gradually decolorized the MO solution. The reduction of MO was concurrently monitored after every 2 minute period of time by using an Ultraviolet-Visible (UV-Vis) spectrophotometer. About $1 \mathrm{~mL}$ aliquots were taken for UVVis analysis and the sample that was taken for UV-Vis analysis was reintroduced into the catalysis reaction flask. The UV-Vis spectrophotometer monitored the lowering of the characteristic absorbance of MO at $464 \mathrm{~nm}$ with respect to time. ${ }^{36}$

2.4.2 Formic acid oxidation and the concurrent reduction of MO. In a $125 \mathrm{~mL}$ Erlenmeyer flask, to $100 \mathrm{~mL}$ of $20 \mathrm{ppm} \mathrm{MO}$ solution, a full PtNPs@KWP was added. Afterward, $50 \mu \mathrm{L}$ of FA was added, mixed quickly and continuously stirred on a magnetic stirring plate. The addition of FA decreased the $\mathrm{pH}$ of the solution to $\sim 3.0$ and the characteristic absorption maximum of MO at $464 \mathrm{~nm}$ was found to redshift to $515 \mathrm{~nm}$. Therefore, the reaction course was monitored by monitoring the absorbance of MO at $515 \mathrm{~nm}$. Every $2 \mathrm{~min}, 1 \mathrm{~mL}$ sample was taken for UV-Vis analysis and after the analysis, the samples were reintroduced into the reaction flask.

2.4.3 Catalytic reduction of MO in simulated fresh drinking water. In order to investigate the efficiency and the real-life applicability of the PtNPs@KWP, the FA and the $\mathrm{H}_{2}$ induced catalytic reductions of MO were carried out in simulated fresh drinking water (FDW). The simulated FDW contained different ions such as carbonate, bicarbonate, chloride, phosphate, sodium, calcium, and magnesium ions, among others. For the $\mathrm{H}_{2}$ gas induced reduction, the same procedure that was utilized for DI water was followed. However, for the FA induced catalytic reduction, it was observed that addition of 50 $\mu \mathrm{L}$ FA into $100 \mathrm{~mL}$ of $20 \mathrm{ppm}$ MO solution did not lower the $\mathrm{pH}$ to 3.0 as it did in the case of DI water. It was found that $200 \mu \mathrm{L}$ of FA was needed to lower the $\mathrm{pH}$ of the MO solution in FDW to 3.0. Therefore, for the FA-induced reduction of MO in FDW, 200 $\mu \mathrm{L}$ of FA was used in $100 \mathrm{~mL}$ of $20 \mathrm{ppm}$ MO solution. It is well known that the FA oxidation works efficiently in acidic $\mathrm{pH}$.

2.4.4 Reaction kinetics. The concentrations of FA and $\mathrm{H}_{2}$ gas used in the catalysis were much higher than the concentration of the substrate (MO), and therefore the concentrations of FA and $\mathrm{H}_{2}$ gas can be considered to be constant. Therefore, pseudo-first-order kinetics with respect to MO could be applied to evaluate the reaction rate. The linear form of the pseudo-firstorder kinetic model is expressed by eqn (1).

$$
\text { Pseudo-first-order rate equation : }-\ln \frac{C_{t}}{C_{\mathrm{o}}}=k t
$$

where $k(1 / \mathrm{min})$ represents the pseudo-first-order rate constant of the catalytic reduction, and $C_{0}$ and $C_{t}$ represent the initial and time-dependent concentrations of MO.

The \% reduction of MO was calculated using eqn (2).

$$
\text { Reduction }(\%)=\frac{C_{0}-C_{t}}{C_{0}}=\frac{A_{0}-A_{t}}{A_{0}} \times 100 \%
$$

where $C_{0}$ and $C_{t}$ represent the concentrations of $\mathrm{MO}\left(\mathrm{mg} \mathrm{L}^{-1}\right)$ at the beginning and at time $t$, respectively. $A_{0}$ and $A_{t}$ represent the absorbance of $\mathrm{MO}$ at concentrations $C_{0}$ and $C_{t}$, respectively.

\section{Characterization of the PtNPs and PtNPsaKWP}

\subsection{TEM image and UV-Vis spectrum of the PtNPs}

The size, shape, size distribution, and $d$-spacing of the PtNPs were studied by transmission electron microscopy. As shown in Fig. 1a, the PtNPs can be seen as both spherical and semispherical in shape. As the PtNPs were ultrasmall in size, they were not perfectly spherical in shape. The PtNPs were found as individual particles and in the form of small aggregations (Fig. 1a). The average diameter and size distribution of the PtNPs were determined using ImageJ software, and the results are shown in Fig. 1b. It was found that the particle size varied from 0.75 to $4.5 \mathrm{~nm}$ with an average diameter of $2.25 \mathrm{~nm}$.

The HRTEM image of the PtNPs is shown in Fig. 1c. The lattice spacing of $0.22 \mathrm{~nm}$ can be clearly seen, and it corresponds to the $d$-spacing of the Pt (111) plane of the facecentered-cubic (FCC) crystal structure of the PtNPs. This eventually confirmed the nanocrystalline structure of the PtNPs.
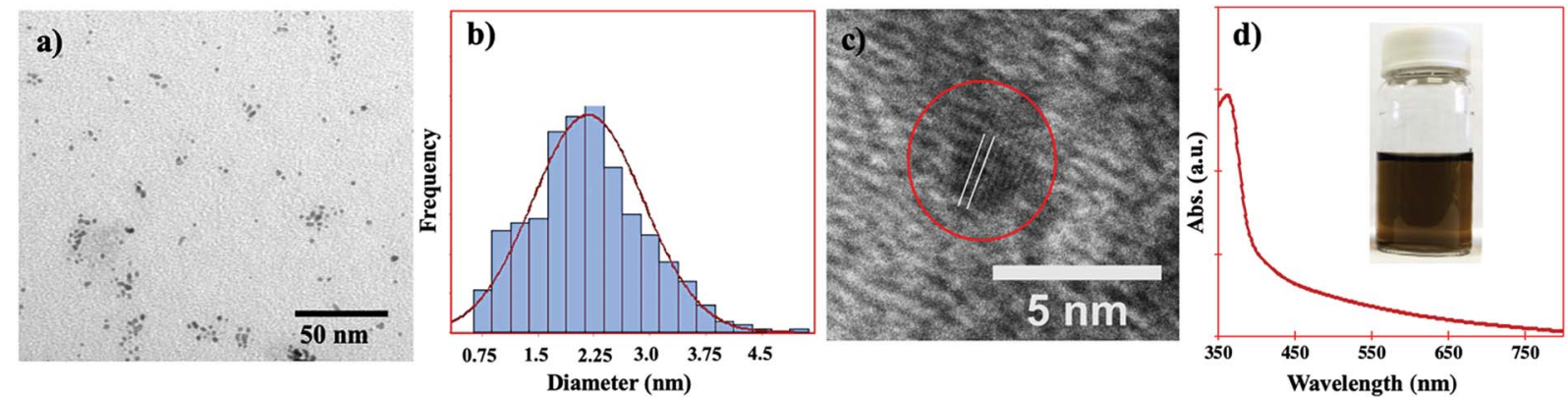

Fig. 1 (a) Typical TEM image of the PtNPs in water, (b) size distribution of the PtNPs, (c) HRTEM image of the PtNPs showing the $d$-spacing of the (111) crystalline plane, and (d) UV-visible spectrum of the PtNP solution in water. Inset: digital photograph of the PtNPs in water. 
The UV-visible spectrum and the digital photograph of the PtNP solution in water are shown in Fig. 1d. No surface plasmon resonance (SPR) absorption band was observed in the visible range of electromagnetic radiation, which is similar to other reports. ${ }^{37}$ Sometimes the SPR band of PtNPs can be found in the ultraviolet region, and it may have overlapped with the absorption band of the rhodizonate ion, in this case. As sodium rhodizonate is yellow in color it generated a strong absorption band and absorption tail in the $\mathrm{UV}$ (e.g. at $365 \mathrm{~nm}$ ) and visible regions of the spectrum, respectively (as shown in Fig. 1d). Therefore, due to the presence of excess rhodizonate ions, the PtNP solution could be seen as yellowish brown in color (Fig. 1d inset).

\subsection{SEM and TEM images, and EDX of the PtNPs@KWP}

A SEM image of the PtNPs@KWP is shown in figure. The SEM images revealed the fibrous morphology of the macroporous cellulose fibers obtained from Kimwipe paper. The fibers could be seen intertwined together with a high aspect ratio. Morphology-wise, the fibers were seen as flattened and elongated having a width of about $20 \mu \mathrm{m}$. SEM image analysis further revealed the porous morphology of the cellulose fibers as seen in Fig. $2 b$.

Fig. 2b and c show the KWP bound PtNPs (PtNPs@KWP) at different magnifications. It was observed that the PtNPs were well distributed on the surface of the cellulose fibers due to the binding integrations between the cellulose fibers and PtNPs. Compared to the PtNPs in solution, the PtNPs on KWP were found to be somewhat more aggregated (Fig. 2c).

The EDX spectrum of PtNPs@KWP showed the presence of a high abundance of carbon and oxygen with a relatively lower abundance of platinum (Fig. 2d). The weak platinum intensity in the EDX spectrum could be attributed to the low platinum loading ( $c a .0 .87 \mathrm{wt} \%$ ) on the KWP. This presence of platinum in the EDX spectrum further indicates the successful binding of the PtNPs with the KWP. The binding of the PtNPs on the KWP could also be seen by the naked eye. The pristine white KWP turned grayish brown in color, which resulted from the incorporation of the PtNPs into the KWP (Fig. 2d).

\subsection{XRD pattern and BET surface area of the PtNPs@KWP}

The PtNPs@KWP was further characterized by XRD analysis to reveal the crystalline properties of the cellulose fibers and the PtNPs. As shown in Fig. 3, diffraction peaks were observed at $2 \theta=$ $15.4^{\circ}, 16.2^{\circ}$, and $22.7^{\circ}$, and can be attributed to the 100,010 and 110 crystalline faces of the cellulose I $\alpha$ allomorph, or the 10, 110, and 200 crystalline faces of the cellulose I $\beta$ allomorph. ${ }^{38,39}$ The XRD patterns of these two allomorphs of cellulose are very similar and the XRD peaks are usually located very close to each other, and therefore it is difficult to distinguish them from XRD study only.

In addition to the diffraction peaks of the crystalline cellulose fibers, three weak peaks located at $2 \theta=39.8^{\circ}, 46.4^{\circ}$, and $67.7^{\circ}$ were observed, which are characteristic of the (111), (200), and (220) diffraction planes of the crystalline $\mathrm{Pt}(0)$ nanoparticles, respectively (JCPDS card no. 04-0802). ${ }^{40}$ This type of XRD pattern further confirms the face-centered cube (fcc) crystalline structure of the PtNPs. ${ }^{41}$

Additionally, the PtNPs@KWP was characterized by nitrogen gas adsorption studies to obtain the specific surface area. The Brunauer-Emmett-Teller (BET) specific surface area of the PtNPs@KWP was measured to be about $0.0816 \mathrm{~m}^{2} \mathrm{~g}^{-1}$ with a pore volume of about $1.344 \mathrm{~mm}^{3} \mathrm{~g}^{-1}$ and a pore size of about 145.449 $\AA$, in complete agreement with other reports..$^{42}$ Previous studies report that the specific surface area of native cellulose ranges from 0.6 to $1 \mathrm{~m}^{2} \mathrm{~g}^{-1}$ with pore volumes of about $2 \mathrm{~mm}^{3} \mathrm{~g}^{-1} \cdot{ }^{43}$

\subsection{High-resolution XPS of the PtNPs@KWP}

A high-resolution X-ray photoelectron spectrum was obtained to analyze the qualitative elemental composition of the PtNPs@KWP. The XPS survey spectrum of the PtNPs@KWP,

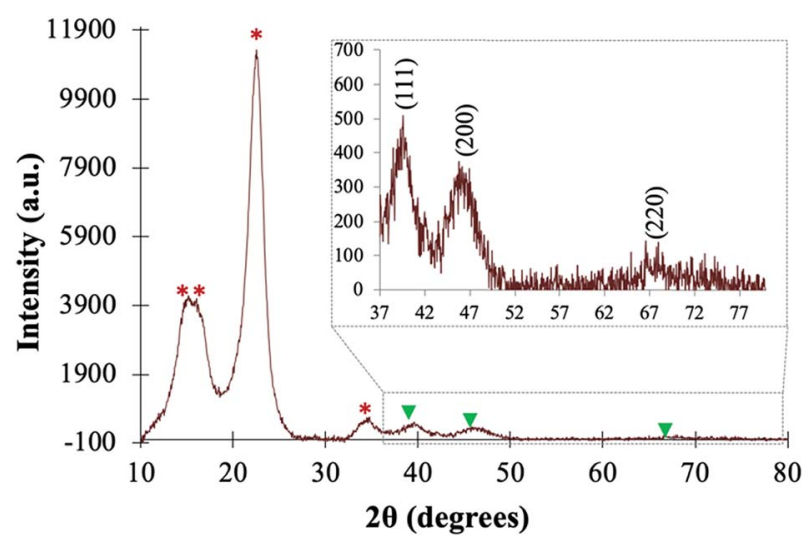

Fig. 3 XRD pattern of the PtNPs@KWP showing the crystallinity of the KWP (peaks marked as *) and the PtNPs (marked as $\boldsymbol{\nabla}$ ). Inset: the FCC crystalline structure of the PtNPs.
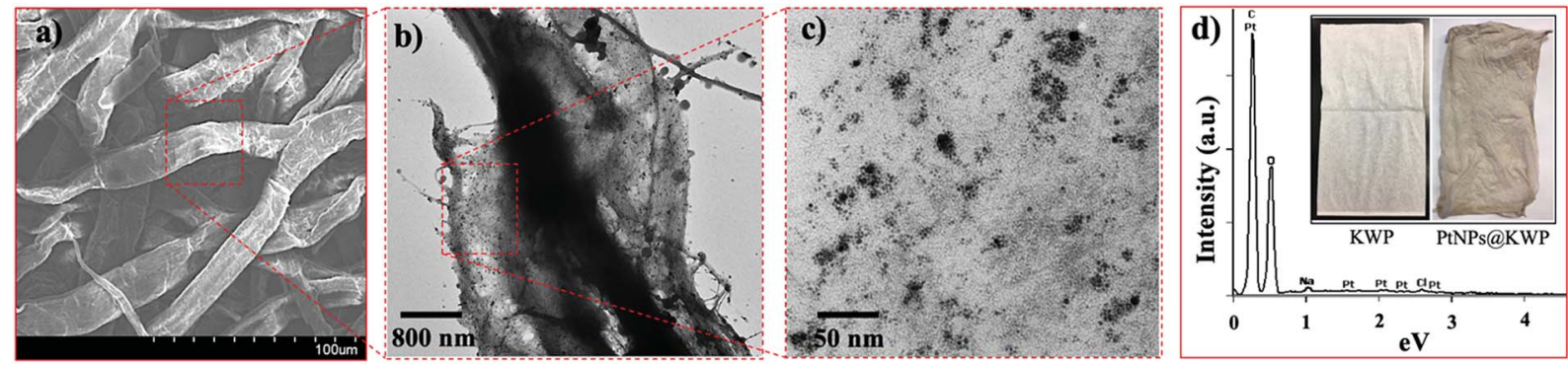

Fig. 2 (a) SEM image of the macroporous cellulose fiber network of KWP, (b and c) TEM images of the PtNPs@KWP at different magnifications, and (d) EDX spectrum of the PtNPs(KWP. Inset: digital photographs of the pristine KWP (left) and PtNP supported KWP (right). 
shown in Fig. 4a, indicated that the PtNPs@KWP is chemically composed of carbon, oxygen, and platinum. High-resolution XPS spectra were obtained to further analyze the oxidation state of the elements. For example, two peaks of Pt $4 \mathrm{f}$ at $71.38 \mathrm{eV}$ (Pt $\left.4 \mathrm{f}_{7 / 2}\right)$ and $74.58 \mathrm{eV}\left(\mathrm{Pt}_{4 \mathrm{f}}\right)$, shown in Fig. $4 \mathrm{~b}$, further indicated that the platinum is present mostly as $\mathrm{Pt}^{0}{ }^{\mathbf{4 3 - 4 5}}$ Additionally, a less intense peak of $\mathrm{Pt} 4 \mathrm{f}$ at $76.38 \mathrm{eV}\left(\mathrm{Pt}_{4 \mathrm{f}_{5 / 2}}\right)$ indicated the presence of $\mathrm{Pt}^{2+}$ species. ${ }^{44,45}$ It could be assumed that the $\mathrm{Pt}^{\mathrm{O}}$ peaks originated from the metallic core of the PtNPs and the $\mathrm{Pt}^{2+}$ peak originated from the ionic surface of the PtNPs. Due to the presence of the $\mathrm{Pt}^{2+}$ ions on the surface, the excess rhodizonate ions could coordinate with them to stabilize the platinum nanoparticles.

The presence of $\mathrm{C}-\mathrm{C}, \mathrm{C}-\mathrm{O}$, and $\mathrm{O}-\mathrm{C}-\mathrm{O}$ bonds was also confirmed by the high-resolution XPS of the C 1s (Fig. 4c). ${ }^{46}$ These bonds can be attributed to the functionalities (e.g. alcohol and ether) that are present in the cellulose fibers.

\section{Results and discussion}

The PtNPs were synthesized by boiling a solution of sodium rhodizonate and $\mathrm{H}_{2} \mathrm{PtCl}_{6}$ in water. The reaction mixture changed color from orange to brownish yellow within 5 min of heating, which indicated the reduction of $\mathrm{Pt}^{4+}$ to $\mathrm{Pt}^{0}$ and the formation of PtNPs. On the other hand, the color of the rhodizonate ion changed from deep orange to light yellow due to its oxidation. Since sodium rhodizonate is the only species used for the synthesis of the PtNPs, it could be inferred that it served as the reducing agent as well as the stabilizing agent. It could be suggested that the excess rhodizonate ions coordinated with the ionic platinum $\left(\mathrm{Pt}^{2+}\right)$ at the surface of the PtNPs to stabilize them. The use of sodium rhodizonate and sodium squarate for the synthesis of noble metal (gold, silver, platinum, and palladium) nanoparticles was reported in our previous studies. ${ }^{47-49}$ The method for synthesising noble metal nanoparticles using sodium rhodizonate was found to be fast, having the ability to form nanoparticles of varying size depending on the temperature of synthesis. Moreover, it was found that the nanoparticles had a strong affinity to bind with the cellulose fibers, which indicated the ligand exchangeability of the nanoparticles. This also indicated that the PtNPs had an active surface able to catalyze various chemical reactions.

A systematic mechanism for the reduction of $\mathrm{Au}^{3+}$ to $\mathrm{Au}^{0}$ by sodium squarate was proposed by Nathaniel E. Larm and colleagues. $^{50}$ Moreover, Shuangming Chen and colleagues proposed a mechanism for the reduction of $\mathrm{Pt}^{4+}$ to $\mathrm{Pt}^{0}$ in a methanol-water system. ${ }^{51}$ Based on the findings of their mechanistic studies, we propose a mechanism for the reduction of $\mathrm{Pt}^{4+}$ to $\mathrm{Pt}^{0}$ in conjunction with the oxidation of sodium rhodizonate (Scheme 1). The overall mechanism for the reduction of $\mathrm{Pt}^{4+}$ to $\mathrm{Pt}^{0}$ can be split into four steps viz. (I) ligand exchange, (II) $\left[\mathrm{PtCl}_{6}\right]^{2-}$ reduction to $\left[\mathrm{PtCl}_{2}\right]^{2-}$, (III) loss of $\mathrm{Cl}^{-}$and the aggregation of $\left[\mathrm{PtCl}_{2}\right]^{2-}$ to form $\mathrm{Pt}^{0}$ nanoclusters, and (IV) hydrolysis of the oxidation product of rhodizonate.

In the ligand exchange step, the enolate oxygen of the rhodizonate ion replaces the $\mathrm{Cl}^{-}$from the $\left[\mathrm{PtCl}_{6}\right]^{2-}$ by nucleophilic substitution (Step I). After the ligand exchange, the rhodizonate ion donates electrons to the $\left[\mathrm{PtCl}_{6}\right]^{2-}$ to reduce it to $\left[\mathrm{PtCl}_{4}\right]^{2-}$. During this electron transfer process, the rhodizonate ion gets oxidized into a cyclic hexaketone compound and gets dissociated from the complex (Step II). The $\left[\mathrm{PtCl}_{4}\right]^{2-}$ may then get further reduced to zerovalent $\mathrm{Pt}$ atoms viz. $\left[\mathrm{PtCl}_{2}\right]^{2-}$ by two possible pathways viz. reduction by a second rhodizonate ion or by the disproportionation reaction. Afterward, the zerovalent $\mathrm{Pt}$ atoms in the form of $\left[\mathrm{PtCl}_{2}\right]^{2-}$ aggregate together and lose $\mathrm{Cl}^{-}$ ions to form PtNPs (Step III). The excess rhodizonate ions further stabilize the PtNPs by coordination bonds, and therefore the nanoparticles do not grow further to larger (micron) size particles. The oxidation product of the rhodizonate ion viz. the cyclic hexaketone is chemically labile and may undergo hydrolysis to form alcohol derivatives (Step IV).

The as-synthesized PtNPs were supported on KWP due to their macroporosity and chemical functionality. ${ }^{52,53} \mathrm{KWP}$, consisting of highly pure and interweaved cellulose fibers, offers interconnected pores (shown by the SEM image, Fig. 2a) that can host nanostructured materials. When a piece of KWP was immersed in the aqueous PtNP solution, the PtNPs were readily impregnated into the cellulose fibers through these pores. Moreover, due to the abundance of the polarized functionality (e.g. $\mathrm{O}-\mathrm{H}$ and $\mathrm{O}-\mathrm{C}-\mathrm{O}$ ) of the cellulose, we assume that the PtNPs were also bound to KWP via electrostatic and non-bonding
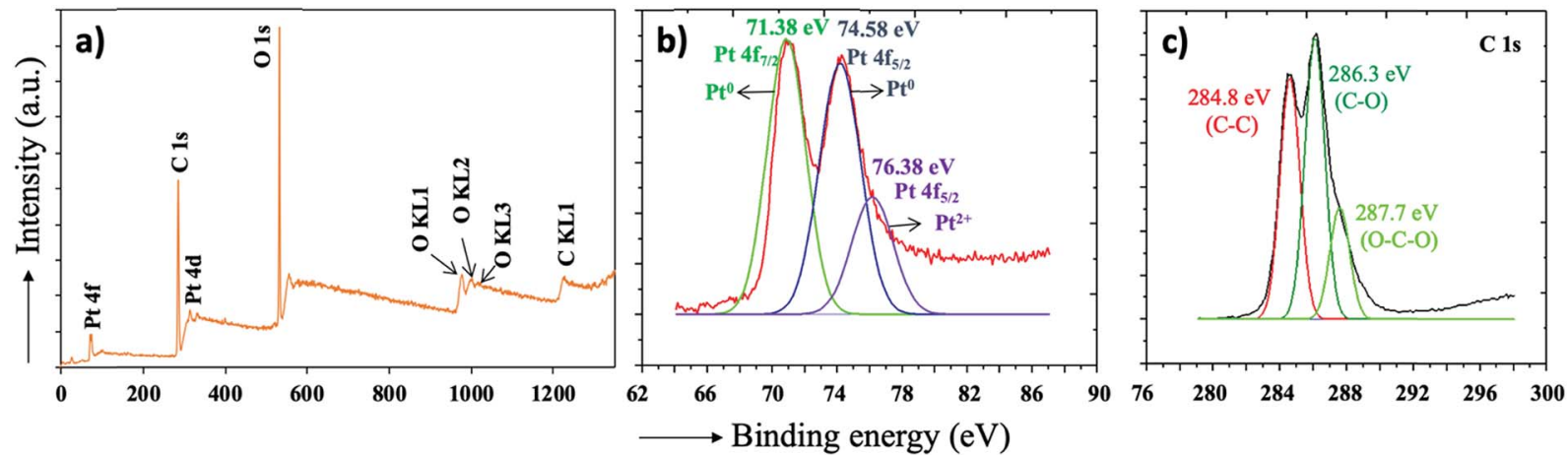

Fig. 4 XPS spectra of the PtNPs@KWP. (a) Survey spectrum of the PtNPs@KWP, (b) high-resolution spectrum of the Pt 4f, and (c) high-resolution spectrum of the $C 1 \mathrm{~s}$. 


\section{Ligand Exchange:}

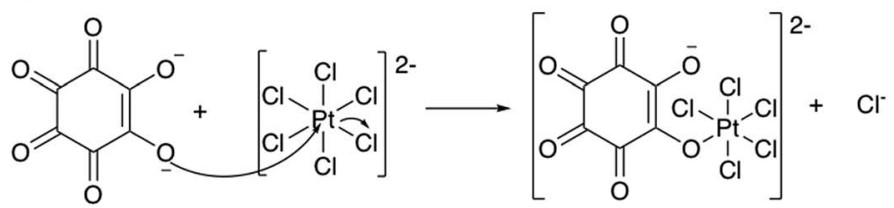

II. Reduction of $\left[\mathrm{PtCl}_{6}\right]^{2-}$ to $\left[\mathrm{PtCl}_{2}\right]^{2-}$ :
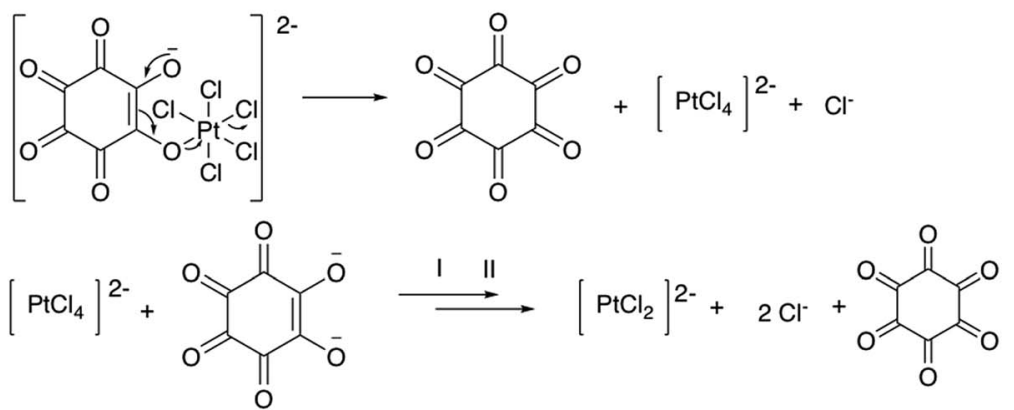

Or, Disproportionation of $\left[\mathrm{PtCl}_{4}\right]^{2-}$ :

$2\left[\mathrm{PtCl}_{4}\right]^{2-} \longrightarrow\left[\mathrm{PtCl}_{2}\right]^{2-}+\left[\mathrm{PtCl}_{6}\right]^{2-}$

III. Aggregation of the $\left[\mathrm{PtCl}_{2}\right]^{2-}$ to form $\mathrm{Pt}^{0}$ clusters :

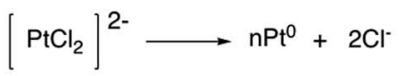

IV. Rhodizonate oxidation byproducts:

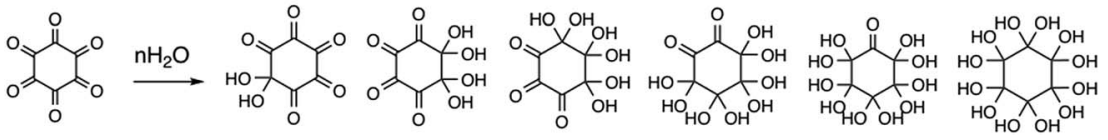

Scheme 1 Proposed mechanism for the reduction of $\left[\mathrm{PtCl}_{6}\right]^{2-}$ to metallic Pt by the rhodizonate ion.

interactions. The electron-rich oxygen atoms of the polar hydroxyl and ether groups of cellulose are considered to interact with electropositive transition metal cations. ${ }^{54}$

The catalytic activity of the PtNPs@KWP towards the reductive degradation of MO by $\mathrm{H}_{2}$ gas and FA is depicted in Scheme 2. In the FA-induced catalysis, the PtNPs@KWP simultaneously catalyzed the oxidation of FA $\left(\text { e.g. } \mathrm{HCOOH} \rightarrow \mathrm{H}_{2}+\mathrm{CO}_{2}\right)^{55}$ and the reduction of $\mathrm{MO}$ to the degradation products.

The oxidation of FA can be catalyzed by many homogeneous and heterogeneous transition metal compounds. ${ }^{56}$ However, the low $\mathrm{pH}$ caused by FA usually dissolves the transition metal catalysts. Therefore, the utilization of noble metal nanoparticles (e.g. PtNPs) is important because of their chemical robustness and better catalytic activity. Additionally, the binding of the NPs on a solid support provides better handling and reuse for the purpose of practical applications.

\subsection{Catalytic reduction of MO using $\mathrm{H}_{2}$ gas}

The time-dependent catalytic reduction of MO and the corresponding kinetics of the reductions are shown in Fig. 5. The timedependent UV-Vis spectrum shows a gradual decrease in the absorbance of MO centered at $464 \mathrm{~nm}$ and $275 \mathrm{~nm}$; however, the origin of a new band at $245 \mathrm{~nm}$ suggests the formation of other compounds. The band at $464 \mathrm{~nm}$ arises from the strong conjugation of MO through the molecule and the band at $285 \mathrm{~nm}$ is attributed to the azo bond $(-\mathrm{N}=\mathrm{N}-)$ of $\mathrm{MO}$, which originated from the $\pi \rightarrow \pi^{*}$ electronic transition. However, the origin of the new absorption band at $245 \mathrm{~nm}$, after the reduction of MO, corresponds to the degradation products of MO viz. 4-aminobenzenesulfonate and 4-N,N-dimenthylaminobenzene. ${ }^{57}$

The time-dependent percent reduction of MO, catalyzed by the PtNPs@KWP, is shown in Fig. 5b. It was found that about $95 \%$ of the MO was reduced after $6 \mathrm{~min}$ of reaction and afterward, the reduction became slow. However, after 10 min more than $99 \%$ of the MO was reduced. In contrast, the uncatalyzed reduction, where pristine KWP was used, demonstrated about $1.6 \%$ decolorization of MO after $10 \mathrm{~min}$. Therefore, it could be concluded that the PtNPs bound to the KWP are responsible for

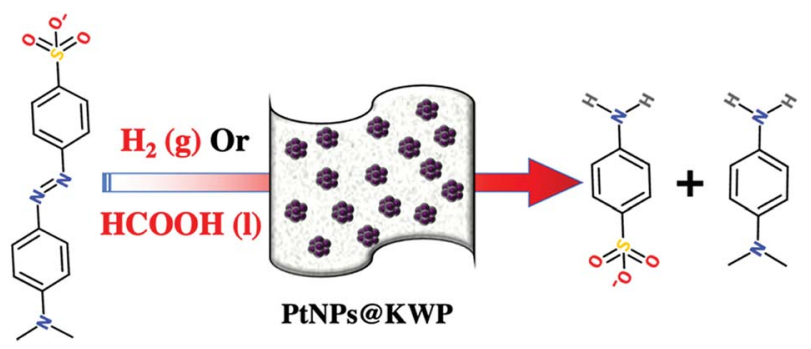

\section{Methyl orange}

Reduced species

Scheme 2 The PtNPs@KWP catalyzed reduction of MO in the presence of $\mathrm{H}_{2}$ gas and formic acid. 

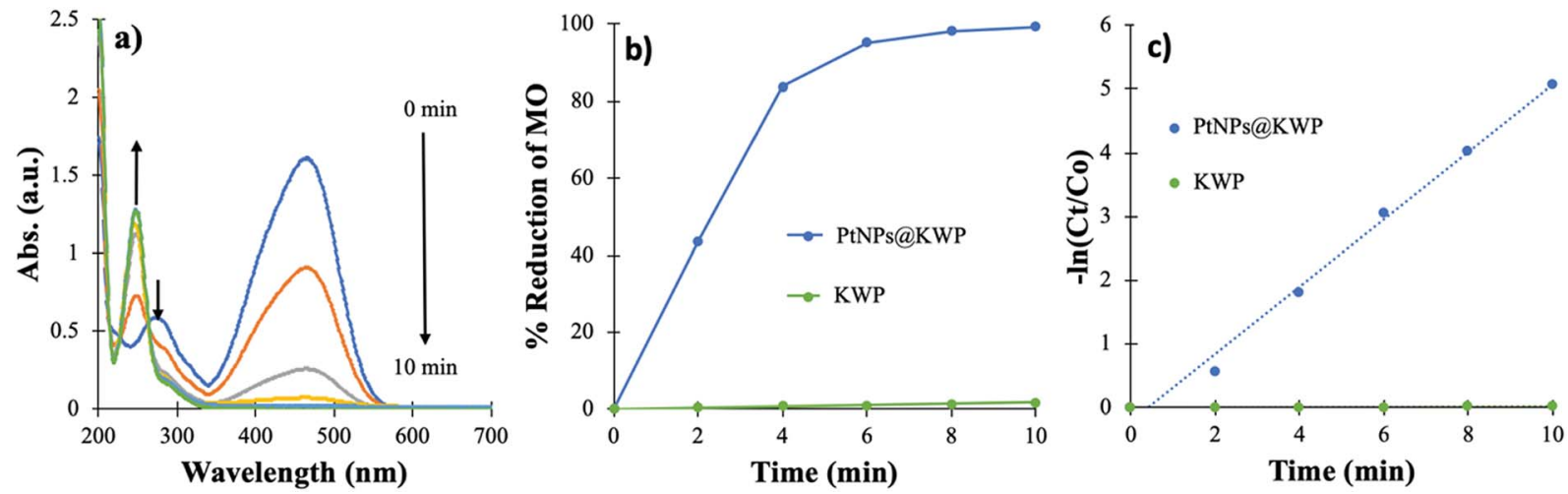

Fig. 5 (a) Time-dependent UV-Vis spectrum of MO solution during catalysis, (b) time-dependent percent reduction of MO, and (c) pseudo-firstorder kinetics of $\mathrm{MO}$ reduction.

the catalysis. The pseudo-first-order kinetics of the catalytic reduction is shown in Fig. $5 \mathrm{c}$. The apparent rate constant $\left(k_{\text {app }}\right)$ of the PtNPs@KWP catalyzed reaction, obtained from the slope of the $\ln \left(C_{t} / C_{0}\right) v s$. time line, was calculated to be $0.529 \mathrm{~min}^{-1}$. However, the $k_{\text {app }}$ of the uncatalyzed reaction was calculated to be $0.0017 \mathrm{~min}^{-1}$. Therefore, it was found that the PtNPs@KWP catalyzed the reduction of MO 311 times faster than what was achieved in the uncatalyzed reaction.

\subsection{Catalytic oxidation of FA followed by the reduction of MO}

Fig. 6 shows the time-dependent decrease in the absorbance of MO centered at $515 \mathrm{~nm}$ with the corresponding kinetics of the reduction. It could be noted that $\mathrm{MO}$ in acidic $\mathrm{pH}$ gives redshifted absorption maxima at $\sim 515 \mathrm{~nm}$ due to the quinonoid benzene ring resonance system of MO. ${ }^{58}$ The addition of $20 \mu \mathrm{L}$ FA into $100 \mathrm{~mL} 20 \mathrm{ppm}$ MO solution lowered the $\mathrm{pH}$ to $\sim 3$. In the time-dependent UV-Vis spectrum, it could be observed that within 6 min MO was completely reduced to the corresponding reduced species. The absorption bands at 515, 275, and $325 \mathrm{~nm}$ disappeared completely; however, a new band appeared at $245 \mathrm{~nm}$. The 285 and $325 \mathrm{~nm}$ absorption bands correspond to the azo $(-\mathrm{N}=\mathrm{N}-)$ bond of MO. As discussed above, a new absorption band appears at $250 \mathrm{~nm}$, corresponding to the degradation products of MO viz. 4-aminobenzenesulfonate and 4- $N, N$-dimenthylaminobenzene.

As shown in Fig. 6b, more than $99 \%$ of the MO was reduced after 6 min of reaction, which is a little faster than the $\mathrm{H}_{2}$ gas catalyzed reduction. This indicates that the in situ generated $\mathrm{H}_{2}$ gas works faster than the $\mathrm{H}_{2}$ gas bubbled catalysis. The uncatalyzed reduction demonstrated about 17\% decolorization of MO after $10 \mathrm{~min}$, which is due to the adsorption of MO on the KWP. Likewise, in the $\mathrm{H}_{2}$ gas bubbled catalysis, the $-\ln \left(C_{t} / C_{0}\right)$ $v s$. time $(t)$ plot is a straight line which indicates that the reactions follow pseudo-first-order kinetics. The $k_{\text {app }}$ of the catalyzed reaction was calculated to be $0.891 \mathrm{~min}^{-1}$, which is higher than that of the $\mathrm{H}_{2}$ gas induced catalysis.

\subsection{Catalytic reduction of MO in simulated water}

The effectiveness and the applicability of the PtNPs@KWP were further determined by carrying out the catalysis in simulated FDW. The simulated FDW contained dissolved metallic and non-metallic ions $\left(\mathrm{NaHCO}_{3}, \mathrm{CaCl}_{2}, \mathrm{MgSO}_{4}, \mathrm{Na}_{2} \mathrm{SiO}_{3}, \mathrm{NaNO}_{3}\right.$, $\mathrm{NaF}$, and $\mathrm{NaH}_{2} \mathrm{PO}_{4}$ ), and therefore the effect of these ions on the catalytic efficiency was further determined. Fig. 7 shows the utilization of PtNPs@KWP for the catalytic reduction of MO in the presence of $\mathrm{H}_{2}$ gas and FA in FDW. The PtNPs@KWP catalyzed the reduction of MO using $\mathrm{H}_{2}$ catalysis which achieved
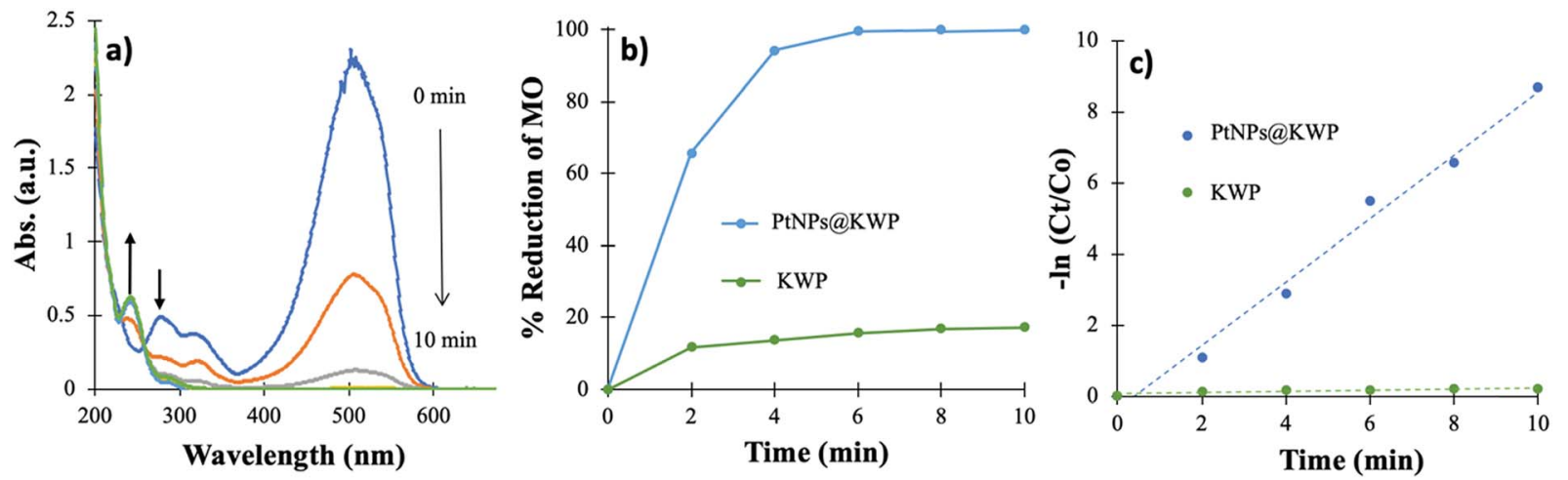

Fig. 6 (a) Time-dependent UV-vis spectrum of MO solution during the catalysis, (b) time-dependent percent reduction of MO, and (c) pseudofirst-order kinetics of $\mathrm{MO}$ reduction. 

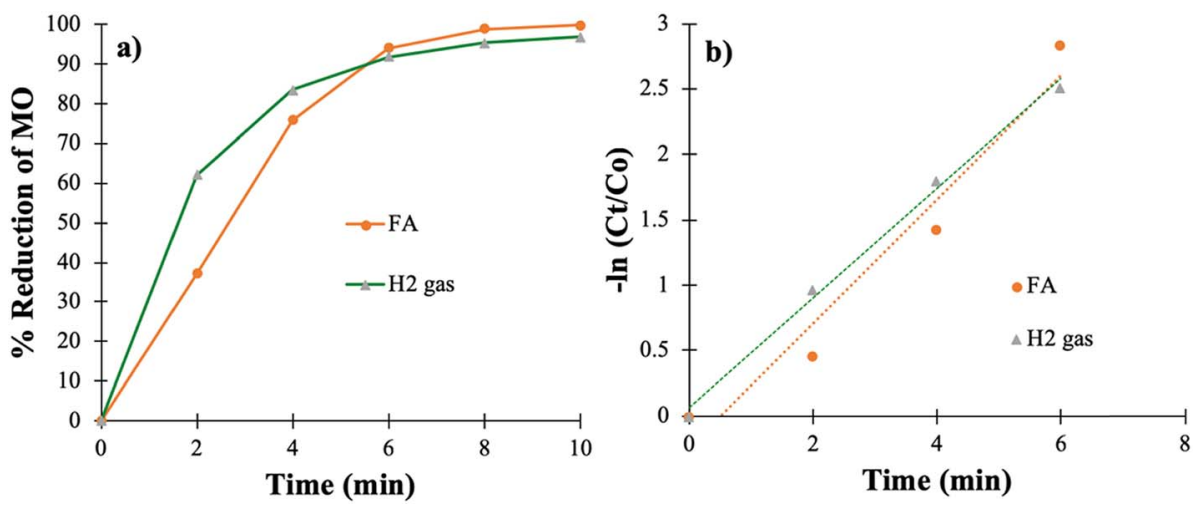

Fig. 7 Catalytic reduction of $\mathrm{MO}$ in simulated FDW by $\mathrm{H}_{2}$ gas and FA using PtNPs@KWP as the catalyst: (a) percent reduction of MO, and (b) pseudo-first-order kinetics of the reduction.

about $97 \%$ reduction of $\mathrm{MO}$ after $10 \mathrm{~min}$. However, for the reduction of MO using $\mathrm{FA}$, the reduction percentage reached about $99.8 \%$ after $10 \mathrm{~min}$.

It could be observed that the PtNPs@KWP catalyzed reduction of MO in FDW was somewhat less active than in deionized water, which could be due to the presence of different ions in the simulated FDW. Similar to the catalysis in deionized water, the catalysis in FDW also followed the pseudo-first-order reaction kinetics (Fig. 7b). The $k_{\text {app }}$ values for the $\mathrm{H}_{2}$ gas and the FAinduced catalytic reduction of $\mathrm{MO}$ in simulated FDW are calculated to be 0.419 and $0.474 \mathrm{~min}^{-1}$, respectively.

\subsection{Cycling stability of the PtNPs@KWP}

The cycling stability of the catalyst is extremely important for the purpose of practical applications, especially when noble metals are used. The cycling stability of the PtNPs@KWP was determined in two different ways. Firstly, the PtNPs@KWP was used for at least five cycles for each type of catalysis. For FA-induced catalysis, the PtNPs@KWP was used for five consecutive cycles on the same day. The PtNPs@KWP was rinsed with DI water between the cycles. For the $\mathrm{H}_{2}$ induced catalysis, a separate PtNPs@KWP was used for five consecutive cycles on the same day and the catalyst was rinsed with DI water after every cycle.

During each cycle, the reaction achieved 99-100\% reduction of MO in a span of ten minutes as can be seen in Fig. 8. A comparison can be made between the FA and the $\mathrm{H}_{2}$ gas induced catalytic reduction of $\mathrm{MO}$, and it can be demonstrated that FA (Fig. 8a) has faster catalytic reducibility than $\mathrm{H}_{2}$ gas (Fig. 8b). The steep curve in Fig. 8a indicates that during each cycle, FA was able to catalytically reduce MO at a faster rate than the $\mathrm{H}_{2}$ gas induced one. The same results were obtained for the catalytic reduction of MO in FDW (Fig. 6).

Secondly, to study the effect of aging, the PtNPs@KWP (that was previously used for the $\mathrm{H}_{2}$ gas induced catalysis) was utilized after 15 days of storage. The PtNPs@KWP was stored hydrated (without drying) under ambient conditions. In this case, the same PtNPs@KWP was used for the $\mathrm{H}_{2}$ gas and subsequently the FA-induced catalytic reduction of MO in DIW, respectively.

Fig. 9 indicates that the 10 day old PtNPs@KWP is as active as the freshly prepared PtNPs@KWP for the reduction of MO by FA and $\mathrm{H}_{2}$ gas. Two consecutive cycles of catalysis of each type were performed to differentiate each experiment and to see if the catalytic activity differed in any way. The results showed consistent and similar activity in both cycles of catalysis. Therefore, it could be concluded that PtNPs@KWP can be used as a robust catalyst for the reduction of $\mathrm{MO}$ in water using $\mathrm{FA}$ or $\mathrm{H}_{2}$ gas.

The cycling stability of the PtNPs@KWP was further studied by carrying out ICP-OES on the solution after the catalytic experiments. The goal was to determine if there was any leaching of the PtNPs into the solution during the catalytic
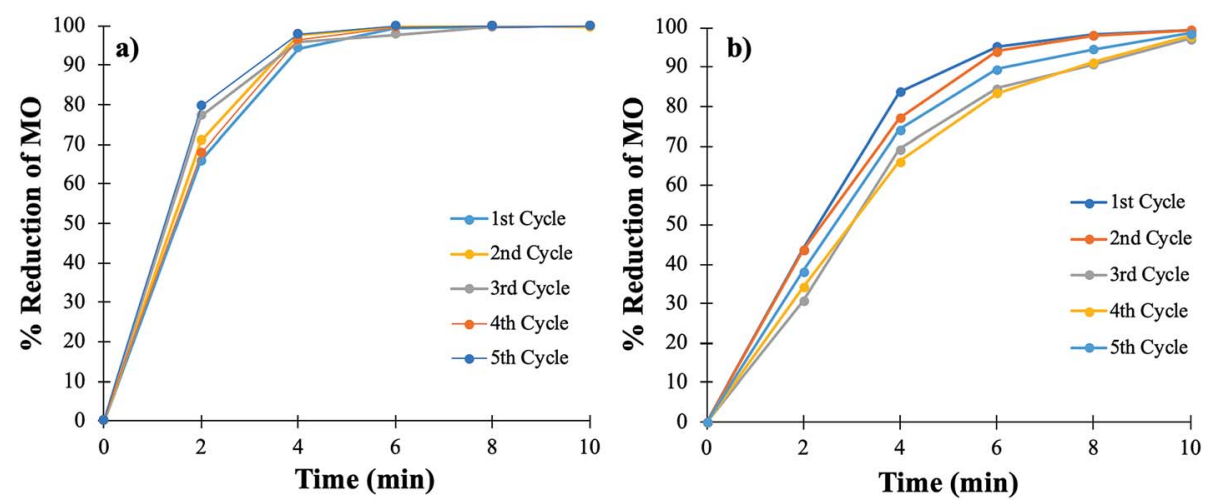

Fig. 8 Cycling stability of the PtNPs@KWP for five consecutive cycles of catalysis. (a) FA and (b) $\mathrm{H}_{2}$ gas induced catalytic reduction of MO. 

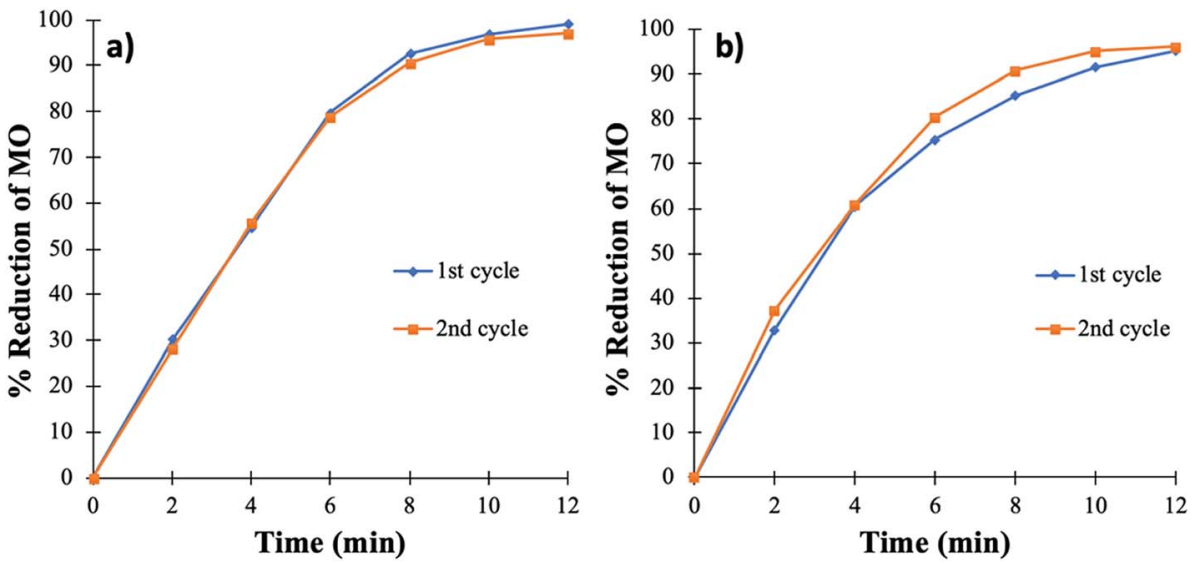

Fig. 9 Catalytic activity of the PtNPs@KWP after 10 days of synthesis. (a) FA and (b) $\mathrm{H}_{2}$ gas induced catalytic reduction of MO.

experiments. For this, a single PtNPs@KWP was used for three cycles of $\mathrm{H}_{2}$ gas and two cycles of FA-induced catalytic reduction of MO solution. After each cycle of catalysis, the decolorized MO solution was stored, acidified, and analyzed by ICP-OES. The ICP-OES results demonstrated that there was an undetectable level (below $10 \mathrm{ppb}$ ) of platinum in each of the MO catalyzed solution. This confirmed that the PtNPs were strongly bound to the cellulose fibers, and they did not detach or dissolve as platinum ions from the KWP. This eventually confirmed the robustness of the PtNPs@KWP towards the catalytic experiments that were carried out in this study.

\subsection{Comparison with the literature}

In Table 1, the catalytic activity of the PtNPS@KWP is compared with the activity of noble metal and transition metal nanoparticles reported in the literature. There was no reported study where platinum nanoparticles were used for the catalytic reduction of MO using $\mathrm{FA}$ and $\mathrm{H}_{2}$ gas as the reducing agents (to the best of our knowledge). Therefore, the performance of our catalyst was compared with that of the reported catalysts that have been used for the reduction of 4-nitrophenol (4-NP) with a large excess of $\mathrm{NaBH}_{4}$ as the reducing agent.

From the comparison table, it can be observed that the PtNPs@KWP demonstrated better catalytic performance than various other noble metal nanoparticle-based catalyst systems reported in the literature. The simplicity of the synthesis methodology of the PtNPs@KWP and its high catalytic performance along with due cycling stability could make it an important catalyst for a wide variety of chemical reactions. Finally, the PTNPs@KWP could be carbonized to prepare carbon supported PtNP nanocomposites that could be utilized for a variety of catalytic and electrocatalytic applications.

\subsection{Mechanism of the FA and $\mathrm{H}_{2}$ gas induced catalytic reduction of MO}

The catalytic oxidation of FA has been demonstrated as a promising method of $\mathrm{H}_{2}$ gas generation, and therefore $\mathrm{FA}$ is considered as a storage medium of $\mathrm{H}_{2}{ }^{65,66}$ The decomposition of FA occurs via several proposed reaction pathways when different catalysts are used. ${ }^{67-69}$ The first pathway is considered

Table 1 Catalytic activity of the PtNPS@KWP: comparison with the literature

\begin{tabular}{|c|c|c|c|c|}
\hline Catalysts & Reductant-substrate & Water matrix & Rate constant $\left(\min ^{-1}\right)$ & References \\
\hline PtNPs@KWP & $\mathrm{H}_{2}-\mathrm{MO}$ & DIW & $5.3 \times 10^{-1}$ & This work \\
\hline PtNPs@KWP & FA-MO & DIW & $8.9 \times 10^{-1}$ & This work \\
\hline PtNPs@KWP & FA-MO & FDW & $4.8 \times 10^{-1}$ & This work \\
\hline $\mathrm{Au} / \mathrm{SNTs}$ & $\mathrm{NaBH}_{4}-4-\mathrm{NP}$ & DIW & $1.8 \times 10^{-2}$ & 59 \\
\hline $\mathrm{Au} / \mathrm{SNTs}$ & $\mathrm{NaBH}_{4}-4 \mathrm{NP}$ & DIW & $4.8 \times 10^{-2}$ & 56 \\
\hline PAMAM dendrimer (G4)-PtNC & $\mathrm{NaBH}_{4}-4 \mathrm{NP}$ & DIW & $1.6 \times 10^{-1}$ & 58 \\
\hline GG-s-PtNPs & $\mathrm{NaBH}_{4}-4 \mathrm{NP}$ & DIW & $4.2 \times 10^{-1}$ & 62 \\
\hline Pt-Ni (4:96) alloy NPs & $\mathrm{NaBH}_{4}-4 \mathrm{NP}$ & DIW & $5.9 \times 10^{-2}$ & 63 \\
\hline PtNPs & $\mathrm{NaBH}_{4}-4 \mathrm{NP}$ & DIW & $7.5 \times 10^{-3}$ & 60 \\
\hline RANEY® $\mathrm{Ni}$ & $\mathrm{NaBH}_{4}-4 \mathrm{NP}$ & DIW & $8.9 \times 10^{-3}$ & 60 \\
\hline PtNPs@polymer brush & $\mathrm{NaBH}_{4}-4 \mathrm{NP}$ & DIW & $5.7 \times 10^{-1}$ & 64 \\
\hline
\end{tabular}


to begin with the dehydrogenation or decomposition of FA (COOH) to yield $\mathrm{H}_{2}$ and $\mathrm{CO}_{2}$ (eqn (3)).

$$
\mathrm{HCOOH} \rightarrow \mathrm{H}_{2}+\mathrm{CO}_{2}\left[\Delta G^{\circ}=-32.9 \mathrm{~kJ} \mathrm{~mol}^{-1}\right]
$$

The in situ generated $\mathrm{H}_{2}$ molecules can chemisorb on the surfaces of the PtNPs and then catalyze the reduction of MO, which is equivalent to the $\mathrm{H}_{2}$ gas bubbled catalytic reduction of MO. The second pathway is considered to happen with the decarbonylation or dehydration of $\mathrm{FA}(\mathrm{HCOOH})$ to produce $\mathrm{CO}$ and $\mathrm{H}_{2} \mathrm{O}$ (eqn (4)).

$$
\mathrm{HCOOH} \rightarrow \mathrm{CO}+\mathrm{H}_{2} \mathrm{O}\left[\Delta G^{\circ}=-20.7 \mathrm{~kJ} \mathrm{~mol}^{-1}\right]
$$

The generated CO then adsorbs onto the PtNP surface, and has the ability to reduce organic and inorganic species while being oxidized to $\mathrm{CO}_{2} \cdot{ }^{70,71}$ The third pathway, also known as the formate pathway, involves the formation of formate and its subsequent oxidation to $\mathrm{CO}_{2}$ and the release of $\mathrm{H}_{2}$ gas. ${ }^{72,73}$ Therefore, either way, FA decomposition can simultaneously reduce organic and inorganic species in the presence of PtNPs. Moreover, the benefit of the utilization of FA is that the decomposition products of FA, viz. $\mathrm{H}_{2}, \mathrm{H}_{2} \mathrm{O}$, and $\mathrm{CO}_{2}$, do not cause secondary pollution while reducing organic pollutants in water.

\section{Conclusions and summary}

In conclusion, we report a simple and fast method for the synthesis of ultrasmall PtNPs in water using sodium rhodizonate. The PtNPs were supported on macroporous cellulose fibers that were obtained from KWP. The cellulose fiber supported PtNPs demonstrated excellent catalytic activity and superior stability towards the reduction of MO in the presence of FA and $\mathrm{H}_{2}$ gas. The results of this study indicate that FA and $\mathrm{H}_{2}$ gas can be utilized as clean and environmentally benign reducing agents for the reductive degradation of organic pollutants in water. The findings of this study can be extended to the catalytic reduction of other organic and inorganic pollutants for the purpose of water remediation.

\section{Conflicts of interest}

The authors declare no conflicting financial interest.

\section{Acknowledgements}

Financial support from NSF grants ERC NanotechnologyEnabled Water Treatment Center 1449500, CHE-0748913, DMR PREM-1205302, and USDA 2014-38422-22078 are gratefully acknowledged. The authors would like to thank Dr Dino Villagran's research group for their kind assistance with the BET surface area analysis.

\section{References}

1 M. Haruta, T. Kobayashi, H. Sano and N. Yamada, Novel gold catalysts for the oxidation of carbon monoxide at a temperature far below 0 C, Chem. Lett., 1987, 16(2), 405-408.
2 A. Corma, P. Concepción, M. Boronat, M. J. Sabater, J. Navas, M. J. Yacaman and E. Mendoza, Exceptional oxidation activity with size-controlled supported gold clusters of low atomicity, Nat. Chem., 2013, 5(9), 775.

3 L. Bai, S. Zhang, Q. Chen and C. Gao, Synthesis of ultrasmall platinum nanoparticles on polymer nanoshells for sizedependent catalytic oxidation reactions, ACS Appl. Mater. Interfaces, 2017, 9(11), 9710-9717.

4 H. U. I. Zhang, M. Jin, Y. Xiong, B. Lim and Y. Xia, Shapecontrolled synthesis of Pd nanocrystals and their catalytic applications, Acc. Chem. Res., 2012, 46(8), 1783-1794.

5 J. Solla-Gullon, F. J. Vidal-Iglesias and J. M. Feliu, Shape Dependent Electrocatalysis, Annu. Rep. Prog. Chem., Sect. C: Phys. Chem., 2011, 107, 263-297.

6 P. Lara and K. Philippot, The hydrogenation of nitroarenes mediated by platinum nanoparticles: An overview, Catal. Sci. Technol., 2014, 4(8), 2445-2465.

7 F. Sen, Y. Karatas, M. Gulcan and M. Zahmakiran, Amylamine stabilized platinum (0) nanoparticles: active and reusable nanocatalyst in the room temperature dehydrogenation of dimethylamine-borane, RSC Adv., 2014, 4(4), 1526-1531.

8 B. Yue, Y. Ma, H. Tao, L. Yu, G. Jian, X. Wang and Z. Hu, CN x nanotubes as catalyst support to immobilize platinum nanoparticles for methanol oxidation, J. Mater. Chem., 2008, 18(15), 1747-1750.

9 S. Jansat, M. Gómez, K. Philippot, G. Muller, E. Guiu, C. Claver and B. Chaudret, A case for enantioselective allylic alkylation catalyzed by palladium nanoparticles, J. Am. Chem. Soc., 2004, 126(6), 1592-1593.

$10 \mathrm{~J}$. Choi and G. C. Fu, Transition metal-catalyzed alkyl-alkyl bond formation: another dimension in cross-coupling chemistry, Science, 2017, 356(6334), eaaf7230.

11 T. Pradeep, Noble metal nanoparticles for water purification: a critical review, Thin Solid Films, 2009, 517(24), 6441-6478.

12 J. Zheng and L. Zhang, Rational design and fabrication of multifunctional catalyzer $\mathrm{CO} 2 \mathrm{SnO} 4-\mathrm{SnO} 2 / \mathrm{GC}$ for catalysis applications: Photocatalytic degradation/catalytic reduction of organic pollutants, Appl. Catal., B, 2018, 231, 34-42.

13 M. T. Islam, H. Jing, T. Yang, E. Zubia, A. G. Goos, R. A. Bernal and J. C. Noveron, Fullerene stabilized gold nanoparticles supported on titanium dioxide for enhanced photocatalytic degradation of methyl orange and catalytic reduction of 4-nitrophenol, J. Environ. Chem. Eng., 2018, 6(4), 3827-3836.

14 R. A. Soomro, A. Nafady, Sirajuddin, S. T. H. Sherazi, N. H. Kalwar, M. R. Shah and K. R. Hallam, Catalytic Reductive Degradation of Methyl Orange Using Air Resilient Copper Nanostructures, J. Nanomater., 2015, 16, 120.

15 L. A. Shah, A. Haleem, M. Sayed and M. Siddiq, Synthesis of sensitive hybrid polymer microgels for catalytic reduction of organic pollutants, J. Environ. Chem. Eng., 2016, 4, 3492-3497.

16 K. Esumi, R. Isono and T. Yoshimura, Preparation of PAMAM - and PPI- metal (silver, platinum, and palladium) nanocomposites and their catalytic activities for reduction of 4-nitrophenol, Langmuir, 2004, 20(1), 237-243. 
17 M. Šimšíková, M. Bartoš, J. Čechal and T. Šikola, Decolorization of organic dyes by gold nanoflowers prepared on reduced graphene oxide by tea polyphenols, Catal. Sci. Technol., 2016, 6(9), 3008-3017.

18 S. Gu, Y. Lu, J. Kaiser, M. Albrecht and M. Ballauff, Kinetic analysis of the reduction of 4-nitrophenol catalyzed by $\mathrm{Au} /$ Pd nanoalloys immobilized in spherical polyelectrolyte brushes, Phys. Chem. Chem. Phys., 2015, 17(42), 28137-28143.

19 L. Zhang, Y. Guo, A. Iqbal, B. Li, M. Deng, D. Gong and W. Qin, Palladium nanoparticles as catalysts for reduction of Cr (VI) and Suzuki coupling reaction, J. Nanopart. Res., 2017, 19(4), 150.

20 V. Grozovski, J. Solla-Gullón, V. Climent, E. Herrero and J. M. Feliu, Formic acid oxidation on shape-controlled Pt nanoparticles studied by pulsed voltammetry, J. Phys. Chem. C, 2010, 114(32), 13802-13812.

21 M. Yadav and Q. Xu, Catalytic chromium reduction using formic acid and metal nanoparticles immobilized in a metal-organic framework, Chem. Commun., 2013, 49(32), 3327-3329.

22 G. V. Lowry and M. Reinhard, Hydrodehalogenation of 1-to 3-carbon halogenated organic compounds in water using a palladium catalyst and hydrogen gas, Environ. Sci. Technol., 1999, 33, 1905-1910.

23 M. Celebi, M. Yurderi, A. Bulut, M. Kaya and M. Zahmakiran, Palladium nanoparticles supported on amine-functionalized $\mathrm{SiO} 2$ for the catalytic hexavalent chromium reduction, Appl. Catal., B, 2016, 180, 53-64.

24 G. V. Lowry and M. Reinhard, Hydrodehalogenation of 1-to 3-carbon halogenated organic compounds in water using a palladium catalyst and hydrogen gas, Environ. Sci. Technol., 1999, 33, 1905-1910.

25 R. A. Johnstone, A. H. Wilby and I. D. Entwistle, Heterogeneous catalytic transfer hydrogenation and its relation to other methods for reduction of organic compounds, Chem. Rev., 1985, 85(2), 129-170.

26 W. B. Mbarek, M. Azabou, E. Pineda, N. Fiol, L. Escoda, J. J. Sunol and M. Khitouni, Rapid degradation of azo-dye using Mn-Al powders produced by ball-milling, RSC Adv., 2017, 7(21), 12620-12628.

27 X. Gu, Z. Lu, H. Jiang, A. Tomoki and Q. Xu, Synergistic catalysis of metal-organic framework-immobilized $\mathrm{Au}-\mathrm{Pd}$ nanoparticles in dehydrogenation of formic acid for chemical hydrogen storage, J. Am. Chem. Soc., 2011, 133, 11822-11825.

28 P. Veerakumar, P. Thanasekaran, K. Lin and S. Liu, Biomass Derived Sheet-like Carbon/Palladium Nanocomposite: An Excellent Opportunity for Reduction of Toxic Hexavalent Chromium, ACS Sustainable Chem. Eng., 2017, 5, 6.

29 M. Dhiman and V. Polshettiwar, Ultrasmall nanoparticles and pseudo-single atoms of platinum supported on fibrous nanosilica (KCC-1/Pt): engineering selectivity of hydrogenation reactions, J. Mater. Chem. A, 2016, 4(32), 12416-12424.

$30 \mathrm{~J}$. Van Rie and W. Thielemans, Cellulose-gold nanoparticle hybrid materials, Nanoscale, 2017, 9, 8525-8554.

31 B. H. Dong and J. P. Hinestroza, Metal nanoparticles on natural cellulose fibers: electrostatic assembly and in situ synthesis, ACS Appl. Mater. Interfaces, 2009, 1, 797-803.
32 J. He, T. Kunitake and A. Nakao, Facile In Situ Synthesis of Noble Metal Nanoparticles in Porous Cellulose Fibers, Chem. Mater., 2003, 15, 4401-4406.

33 L. Bai, S. Zhang, Q. Chen and C. Gao, Synthesis of ultrasmall platinum nanoparticles on polymer nanoshells for sizedependent catalytic oxidation reactions, ACS Appl. Mater. Interfaces, 2017, 9(11), 9710-9717.

34 R. Banerjee, D. A. Chen, S. Karakalos, M. L. C. Piedboeuf, N. Job and J. R. Regalbuto, Ambient Oxidation of Ultrasmall Platinum Nanoparticles on Microporous Carbon Catalyst Supports, ACS Appl. Nano Mater., 2018, 1(10), 5876-5884.

35 D. Kumar, S. B. Lee, C. H. Park and C. S. Kim, Impact of Ultrasmall Platinum Nanoparticle Coating on Different Morphologies of Gold Nanostructures for Multiple One-Pot Photocatalytic Environment Protection Reactions, ACS Appl. Mater. Interfaces, 2017, 10(1), 389-399.

36 M. T. Islam, R. Saenz-Arana, C. Hernandez, T. Guinto, M. A. Ahsan, D. T. Bragg and J. C. Noveron, Conversion of waste tire rubber into a high-capacity adsorbent for the removal of methylene blue, methyl orange, and tetracycline from water, J. Environ. Chem. Eng., 2018, 6(2), 3070-3082.

37 S. Eustis and M. El-Sayed, Noble metal surface plasmon resonance and its enhancement of the radiative and nonradiative properties of nanocrystals of different shapes, Chem. Soc. Rev., 2006, 35, 209-217.

38 C. M. Lee, J. Gu, K. Kafle, J. Catchmark and S. H. Kim, Cellulose produced by Gluconacetobacter xylinus strains ATCC 53524 and ATCC 23768: Pellicle formation, postsynthesis aggregation and fiber density, Carbohydr. Polym., 2015, 133, 270-276.

39 K. Watanabe, M. Tabuchi, Y. Morinaga and F. Yoshinaga, Structural Features and Properties of Bacterial Cellulose Produced in Agitated Culture, Cellulose, 1998, 5, 187-200.

40 J. Rajeswari, B. Viswanathan and T. K. Varadarajan, Tungsten trioxide nanorods as supports for platinum in methanol oxidation, Mater. Chem. Phys., 2007, 106(2-3), 168-174.

41 S. Wang, F. Li, Y. Wang, D. Qiao, C. Sun and J. Liu, A Superior Oxygen Reduction Reaction Electrocatalyst Based on Reduced Graphene Oxide and Iron (II) PhthalocyanineSupported Sub-2 nm Platinum Nanoparticles, ACS Appl. Nano Mater., 2018, 1, 711-721.

42 A. Bismarck, I. Aranberri-Askargorta, J. Springer, T. Lampke, B. Wielage, A. Stamboulis, I. Shenderovich and H. H. Limbach, Surface characterization of flax, hemp and cellulose fibers; surface properties and the water uptake behavior, Polym. Compos., 2002, 23(5), 872-894.

43 W. Liu, P. Rodriguez, L. Borchardt, A. Foelske, J. Yuan, A.-K. Herrmann, D. Geiger, Z. Zheng, S. Kaskel, N. Gaponik, R. Kötz, T. J. Schmidt and A. Eychmüller, Angew. Chem., Int. Ed., 2013, 52, 9849-9852.

44 T. Wang, R. Yang, S. Ouyang, H. Shi and S. Wang, Lightinduced synthesis of clean-surface PdPt@ Pt core-shell nanoparticles with excellent electrocatalytic activity, $R S C$ Adv., 2015, 5(60), 48992-48996.

45 K. Yamamoto, T. Imaoka, W. J. Chun, O. Enoki, H. Katoh, M. Takenaga and A. Sonoi, Nat. Chem., 2009, 1, 397-402. 
46 Q. Liao, X. Su, W. Zhu, W. Hua, Z. Qian, L. Liu and J. Yao, Flexible and durable cellulose aerogels for highly effective oil/water separation, RSC Adv., 2016, 6(68), 63773-63781.

47 Md T. Islam, N. Dominguez, Md. A. Ahsan, H. DomiguezCisneros, P. Zuniga, P. J. J. Alvarez and J. C. Noveron, Sodium rhodizonate induced formation of gold nanoparticles supported on cellulose fibers for catalytic reduction of 4-nitrophenol and organic dyes, J. Environ. Chem. Eng., 2017, 5, 4185-4193.

48 M. T. Islam, R. Saenz-Arana, H. Wang, R. Bernal and J. C. Noveron, Green synthesis of gold, silver, platinum, and palladium nanoparticles reduced and stabilized by sodium rhodizonate and their catalytic reduction of 4nitrophenol and methyl orange, New J. Chem., 2018, 42, 6472-6478.

49 M. T. Islam, J. E. Padilla, N. Dominguez, D. C. Alvarado, M. S. Alam, P. Cooke, M. M. J. Tecklenburg and J. C. Noveron, Green synthesis of gold nanoparticles reduced and stabilized by squaric acid and supported on cellulose fibers for the catalytic reduction of 4-nitrophenol in water, $R S C A d v$., 2016, 6, 91185-91191.

50 N. E. Larm, J. B. Essner, K. Pokpas, J. A. Canon, N. Jahed, E. I. Iwuoha and G. A. Baker, Room-Temperature Turkevich Method: Formation of Gold Nanoparticles at the Speed of Mixing Using Cyclic Oxocarbon Reducing Agents, J. Phys. Chem. C, 2018, 122, 5105-5118.

51 S. Chen, Q. Yang, H. Wang, S. Zhang, J. Li, Y. Wang, W. Chu, Q. Ye and L. Song, Initial reaction mechanism of platinum nanoparticle in methanol-water system and the anomalous catalytic effect of water, Nano Lett., 2015, 15, 5961-5968.

52 D. Ge, L. Yang, L. Fan, C. Zhang, X. Xiao, Y. Gogotsi and S. Yang, Foldable supercapacitors from triple networks of macroporous cellulose fibers, single-walled carbon nanotubes and polyaniline nanoribbons, Nano Energy, 2015, 11, 568-578.

53 Z. Song, T. Ma, R. Tang, Q. Cheng, X. Wang, D. Krishnaraju, R. Panat, C. K. Chan, H. Yu and H. Jiang, Origami lithiumion batteries, Nat. Commun., 2014, 5, 3140.

54 J. He, T. Kunitake and A. Nakao, Facile in situ synthesis of noble metal nanoparticles in porous cellulose fibers, Chem. Mater., 2003, 15(23), 4401-4406.

55 B. Loges, A. Boddien, F. Gärtner, H. Junge and M. Beller, Catalytic Generation of Hydrogen from Formic acid and its Derivatives: Useful Hydrogen Storage Materials, Top. Catal., 2010, 53, 902-914.

56 F. R. Hartley and P. N. Vezey, Supported transition metal complexes as catalysts, Adv. Organomet. Chem., 1977, 15, 189-232.

57 R. A. W. Johnstone and A. H. Wilby, Heterogeneous catalytic transfer hydrogenation and its relation to other methods for reduction of organic compounds, Chem. Rev., 1985, 85, 129-170.

58 J. Kim and B. Van der Bruggen, The Use of Nanoparticles in Polymeric and Ceramic Membrane Structures: Review of Manufacturing Procedures and Performance Improvement for Water Treatment, Environ. Poll., 2010, 158, 2335-2349.
59 J. S. Jan, T. H. Chuang, P. J. Chen and H. Teng, Layer-by-layer polypeptide macromolecular assemblies-mediated synthesis of mesoporous silica and gold nanoparticle/mesoporous silica tubular nanostructures, Langmuir, 2011, 27(6), 2834-2843.

60 T. M. Abdel-Fattah and A. Wixtrom, Catalytic reduction of 4nitrophenol using gold nanoparticles supported on carbon nanotubes, ECS J. Solid State Sci. Technol., 2014, 3(4), M18-M20.

$61 \mathrm{~K}$. Esumi, R. Isono and T. Yoshimura, Preparation of PAMAM - and PPI- metal (silver, platinum, and palladium) nanocomposites and their catalytic activities for reduction of 4-nitrophenol, Langmuir, 2004, 20(1), 237-243.

62 S. Pandey and S. B. Mishra, Catalytic reduction of pnitrophenol by using platinum nanoparticles stabilised by guar gum, Carbohydr. Polym., 2014, 113, 525-531.

63 S. K. Ghosh, M. Mandal, S. Kundu, S. Nath and T. Pal, Bimetallic Pt-Ni nanoparticles can catalyze reduction of aromatic nitro compounds by sodium borohydride in aqueous solution, Appl. Catal., A, 2004, 268(1-2), 61-66.

64 Y. Mei, G. Sharma, Y. Lu, M. Ballauff, M. Drechsler, T. Irrgang and R. Kempe, High catalytic activity of platinum nanoparticles immobilized on spherical polyelectrolyte brushes, Langmuir, 2005, 21(26), 12229-12234.

65 M. Grasemann and G. Laurenczy, Formic acid as a hydrogen source - recent developments and future trends, Energy Environ. Sci., 2012, 5, 8171-8181.

66 J. Fan, Y. Guo, J. Wang and M. Fan, Rapid decolorization of azo dye methyl orange in aqueous solution by nanoscale zerovalent iron particles, J. Hazard. Mater., 2009, 166, 904-910.

67 D. Mellmann, P. Sponholz, H. Junge and M. Beller, Formic acid as a hydrogen storage material - development of homogeneous catalysts for selective hydrogen release, Chem. Soc. Rev., 2016, 45, 3954-3988.

68 Z. Zhao, K. N. Heck, P. Limpornpipat, H. Qian, J. T. Miller and M. S. Wong, Hydrogen-generating behavior of Pddecorated gold nanoparticles via formic acid decomposition, Catal. Today, 2019, 330, 24-31.

69 A. Shokrollahi, F. Zarghampour, S. Akbari and A. Salehi, Solution scanometry, a new method for determination of acidity constants of indicators, Anal. Methods, 2015, 7, 3551-3558.

70 M. Grasemann and G. Laurenczy, Formic acid as a hydrogen source-recent developments and future trends, Energy Environ. Sci., 2012, 5, 8171-8181.

71 P. Veerakumar, P. Thanasekaran, K. C. Lin and S. B. Liu, Biomass Derived Sheet-like Carbon/Palladium Nanocomposite: An Excellent Opportunity for Reduction of Toxic Hexavalent Chromium, ACS Sustainable Chem. Eng., 2017, 5, 5302-5312.

72 L. Zhang, L. Wan, Y. Ma, Y. Chen, Y. Zhou, Y. Tang and T. Lu, Crystalline palladium-cobalt alloy nanoassemblies with enhanced activity and stability for the formic acid oxidation reaction, Appl. Catal., B, 2013, 138, 229-235.

73 Y. X. Chen, M. Heinen, Z. Jusys and R. J. Behm, Bridgebonded formate: active intermediate or spectator species in formic acid oxidation on a Pt film electrode?, Langmuir, 2006, 22(25), 10399-10408. 